\title{
What Makes Inner City High Density Liveable? Insight from Residents in Brisbane, Australia
}

\author{
Laurie Buys \\ School of Design, QUT, GPO Box 2434, Brisbane 4001, Australia \\ Tel: 61-7-3138-1146_E-mail: l.buys@qut.edu.au \\ Desley Vine (Corresponding author) \\ Faculty of Science and Engineering, QUT, GPO Box 2434, Brisbane 4001, Australia \\ Tel: 61-7-3138-7633Ｅ-mail: d.vine@qut.edu.au
}

Evonne Miller

School of Design, QUT, GPO Box 2434, Brisbane 4001, Australia

Tel: 61-7-3138-7633Ｅ-mail: e.miller@qut.edu.au

Received: December 18, 2012 Accepted: January 3, 2013

doi:10.5296/emsd.v2i1.3099ＵＵＵ： Uttp://dx.doi.org/10.5296/emsd.v2i1.3099

\begin{abstract}
Australia's urban form and planning has shifted from traditional individual dwellings on spacious suburban blocks towards higher density urban consolidation. Despite relatively strong market demand for inner city high density (ICHD) living, there is ongoing need to explore and understand the aspects that make this urban form liveable and sustainable. The purpose of this research is to explore the viewpoints of current ICHD residents to better understand the liveability and sustainability matters that affect their everyday experiences and perceptions of this urban form. Qualitative interviews with 24 ICHD Brisbane (Australia) residents illustrates their perceptions and experiences of liveability and the ways in which it is broadly understood within three main domains and nine key sub-concepts, including: individual dwelling (thermal comfort, natural light and balconies, noise mitigation), building complex (shared space, good neighbour protocols, environmental sustainability) and the community (transport, amenities, sense of community). Focussing on the experience of ICHD residents, this research highlights the ways in which multiple aspects of the immediate living
\end{abstract}


environment, the dwelling, building complex and the community intertwine to provide residents with a liveable space. The results show that urban features that reflect current societal pressure for greater sustainability such as lower energy use are the exact same features sought by ICHD residents in determining their liveability. By highlighting the aspects current ICHD residents value most about their dwellings, buildings and communities, these findings will help inform policy-makers, planners, developers and designers as they create urban spaces and dwellings that are more liveable and sustainable.

Keywords: high density, liveability, sustainability, individual dwelling, building complex, community, Brisbane, Australia

\section{Introduction}

As elsewhere in the world, state and local governments in Australia have adopted urban consolidation policies aimed at meeting the main liveability and sustainability objectives of decreasing car dependence and minimising the loss of greenfield areas. This pursuit of a city of short distances involves reducing the physical separation of daily activities and the more effective integration of land use and transport (Howley, Scott, \& Redmond, 2009) thereby reducing car dependency for everyday activities. While the policy of urban consolidation has been positively received by some Australian consumers (Neilson, 2008), traditional suburban housing preferences for a large detached house with a private backyard, continue to work against widespread public acceptance and uptake of consolidation planning initiatives, both in the inner-city and suburban areas (Smart State Council, 2007). Shifting Australians' perceptions so that compact urban living is viewed in a more desirable light will require the coordinated efforts of policy-makers, developers, designers and end-users. This research investigates the views and experiences of inner city high density (ICHD) residents, to provide important insight into how built environments, within the domains of dwelling, building and community, deliver on liveability and sustainability needs in ICHD. ICHD for this study is defined as thirty dwellings per hectare within a five kilometre radius of Brisbane's General Post Office (GPO).

Liveability, like sustainability, is a driving vision of the $21^{\text {st }}$ Century. The two terms are often perceived as synonymous with each other. Indeed, sustainability and liveability concepts often overlap in practice (Andrews, 2001; Evans, 2002; Van Assche, Block, \& Reynaert, 2010; Wheeler, 1999). For example, urban amenity and diversity, mixed uses, sense of place and safety, reduced travel demand and lively and walkable streets are objectives of both liveability and sustainability practice. While there are a lot of similarities between the concepts of liveability and sustainability, the main difference between them is that liveability objectives can be focused on the here and now whereas the objective of sustainability is future generations (Van Assche, et al., 2010). However, if urban consolidation policies are to be successful they need to meet the dual goals of liveability and sustainability (Howley, et al., 2009).

What constitutes a liveable place is complex, very personal and therefore difficult to articulate. 'Liveable' is a commonly used term that lacks a single definition due to its relativistic use for a range of ideas about place-based quality of life. The relativism is implicit 
in this description, as where people choose to live can be considered liveable through their subjective filter. This subjectivity has been one of the major challenges for researchers attempting to develop a more objective based definition of liveable places (Andrews, 2001).

Several researchers have attempted to measure liveability (Andrews, 2001; Myers, 1988; Schmandt \& Bloomberg, 1969; Southworth \& Parthasarathy, 1996). A theory of liveability requires attributes which can be defined and measured. It is important that definitional attributes enable focus on their efficacy and ability to target improvement (Andrews, 2001; Myers, 1989). A theory of daily life has the great advantage of focussing attention on the required elements, regular functioning and social use of place (Chiesura, 2004; Diener, Oishi, \& Lucas, 2003; Lefebvre, 1991). Notions of daily life urbanism have driven much of the recent interest in the New Urbanism, Urban Village, Transit Oriented Development (TOD) and Complete Communities movements (Grant, 2006, 2006a). Within the design fields, notions of daily life are providing a serious rationale for improving the urban environment for regular daily functioning toward the goal of liveability (Bakardjieva, 2003; Grant, 2006; Newman, 2008). A liveability theory of daily life suggests the need to understand the impact, availability and use of elements such as dwelling, building and community on ICHD liveability. Pacione $(1990,2003)$ argues that a daily life perspective is a way of looking at liveability that may help cities and neighbourhoods function better physically, socially and economically to provide for both basic needs and more fulfilling experiences.

Review of the modern urban movements and liveability theorists such as Lynch (1981) Myers (1988) and Whyte (1988, 2001) suggest general agreement on the aspects that contribute to a more liveable place. While rationales differ, there is a significant amount of overlap between the physical attributes which centre on the degree to which a place supports the quality of life, health and wellbeing of occupants. These physical attributes include greater amenity for pedestrians and active public space, resulting in more walkable and liveable cities through densification, mixed land uses and closer proximity to amenities (i.e., residential, commercial, retail, offices, green space and bikeways). Liveable places, are concerned with the quality of space and the built environment, encompassing issues such as safety, ease of use and the physical aesthetics, specifically how dwellings, transport infrastructure and public spaces are planned constructed and connected.

Residential satisfaction studies link liveability to specific features of the home and building, such as dwelling age, size, structure and aesthetic feelings (Lu, 1999), as well as features of the broader neighbourhood, including access to facilities, noise, pollution, safety risks, neighbourhood reputation and social features (Howley, et al., 2009; Sirgy \& Cornwell, 2002). Many researchers and advocacy groups attest to the importance of having a built environment with settings requisite for socialising on a regular basis, community formation and cohesion that is conducive to a sense of belonging and community (Hampshire, 2000; Jacobs, 1961; Myers, 1987, 1988; Whyte, 2001). Overall, liveable communities should "create a comfortable, convenient, efficient and safe public realm and to meet the needs of the full range of users taking into account age, abilities, gender and race” (Rowley, 1998, 154). 


\section{Ml Macrothink}

The liveability theories developed by researchers such as Whyte (1988, 2001), Lynch (1981) and Myers $(1988,1989)$ have been so influential on urban design as to be embodied and incorporated as protocols at the operational level in countries such as the United Kingdom with Urban Design Compendium, New Zealand with Urban Design Protocol and here in Australia with the Australian Urban Design Protocol, the Agenda for Urban Quality in Queensland and the Guide to TOD. Principles of TOD are very much aligned to the physical attributes espoused by the theorists and movements discussed above. TOD principles are designed to create higher density, mixed use neighbourhoods with transit stations developed within 800 metres or a 10 minute walk of high density areas (Crewe \& Forsyth, 2011) thus managing traffic and encouraging widespread public use of well-connected public transportation and other forms of non-car mobility (e.g. walking, cycling) (McCrea \& Walters, 2012).

This research focuses on Brisbane in subtropical Queensland. The Queensland state and local governments are actively pursuing urban consolidation with higher density around transport nodes to create vibrant and active urban spaces using innovative subtropical design (Gleeson \& Steele, 2010; Smart State Council, 2007). With the popularity of urban consolidation policies with governments, it is important to ask how urban liveability and sustainability are affected by ICHD living (Lovejoy, Handy, \& Mokhtarian, 2010; McCrea \& Walters, 2012). There is some debate about the extent to which urban consolidation policies enhance environmental, economic and social sustainability of cities (Ancell \& Thompson-Fawcett, 2008; McCrea \& Walters, 2012). Ancell and Thompson-Fawcett (2008) argue that the compact city ideal has undergone some analysis with regard to environmental sustainability but there has been little evidence to support claims concerning social sustainability outcomes which encompass such aspects as those linked to the dual goals of liveability and sustainability including increased amenity, improved pedestrian and cyclist infrastructure and reduced motor vehicle traffic, air pollution and noise. The purpose of this research is to explore the viewpoints of current ICHD residents to better understand the liveability and sustainability matters that affect their everyday experiences and perceptions of this urban form. Engagement with residents can help modify and enhance definitions and understanding of liveability and sustainability (Wheeler, 1999). Understanding how built environments deliver on liveability and sustainability needs in the context of the everyday is key to improving the desirability of ICHD living.

\section{Method}

\subsection{Participants}

A total of 24 participants (14 men, 10 women) residing in inner city high density (ICHD) Brisbane suburbs were interviewed; half owned their unit, with the remainder paying of a mortgage (7 participants) or renting (5 participants). They had lived in their present accommodation for an average of three years and five months, with only three having children living with them. Ages ranged from 25 to 79 years, with approximately a third in each major age grouping - 25-44 years (7 residents), 45-64 years (9 residents) and 65-79 years (8 residents). The majority were married or in a de facto relationship (14 participants), 
with the remainder single (7 participants), widowed or divorced (3 participants). Over half had a university degree, a combined household annual income over $\mathrm{A} \$ 80,000$ and worked in managerial/professional fields.

\subsection{Procedure}

The study received ethics approval and standard good practice ethical protocols were followed. Interviewees were part of a larger study, with a proportionate sampling technique utilised to mail survey 2311 ICHD (defined as 30 or more dwellings per hectare) residents of six selected precincts (eight suburbs) located within six kilometres of the Central Business District (CBD) of Brisbane, the capital city of Queensland, Australia. There was a 28\% response rate, with 636 surveys (on the positive and negative social, environmental and economic impacts of living in the city) returned. This paper focuses on the qualitative in-depth interviews conducted with 24 residents randomly selected (ensuring range of socio-demographic differences) from those who expressed interest in the survey about participating in further research. Potential interviewees were contacted via email and phone and invited to participate in a face-to-face semi-structured interview (lasting approximately 60 minutes) to explore sustainability impacts of high-density (HD) living. The following areas were broadly covered: likes and dislikes of current dwelling and neighbourhood, social contacts within the dwelling, views on sustainability, transport practices, design perceptions and general opinions about high-density living. This article focuses specifically on perceptions and experiences of what makes ICHD areas liveable and sustainable for residents.

\subsection{Analysis}

Interviews were audio-recorded and later transcribed, with a thematic analysis conducted to identify categories, themes and patterns (Liamputtong \& Ezzy, 2005). Three iterative steps were involved in the thematic analysis. First, transcripts were read and re-read to identify the overarching themes. Second, coding was done manually, with common and contrasting concepts identified, highlighted and grouped. Third, themes were identified, reviewed, categorised and named to create a comprehensive picture of how ICHD residents defined 'liveability' (Liamputtong \& Ezzy, 2005).

\section{Results/Discussion}

Focussing on the experience of residents from ICHD locations, this research highlights the ways in which multiple aspects of the immediate living environment, the unit, building complex and the community intertwine to provide residents with a liveable space. Judgements about liveability are not related to one single identifiable and dominant characteristic of the home or locality, but instead involve a complex array of interconnected domains that can be grouped conceptually as characteristics of the individual dwelling (thermal comfort, natural light and balconies, noise mitigation), building complex (shared space, good neighbourhood protocols, environmental sustainability) and the community (sustainable transport, amenities, sense of community). Table 1 identifies the characteristics conceived to fall within these three domains, which emerged from the data as being important for enhancing the liveability of ICHD areas. Like community quality of life, where isolating 


\section{Macrothink}

just one dimension leads to "issue-specific planning efforts that pay too little attention to the web of interconnections among these dimensions" (National Research Council, 2002, 5), it is essential that each of these domains are conceptualised holistically as inter-related, multi-layered attributes which interlace to determine ICHD residents' judgements of everyday liveability and sustainability. These findings further highlight the importance of a holistic approach to exploring and addressing issues of liveability and sustainability, with various stakeholders, including policy-makers, developers, designers and urban planners, having ultimate responsibility for creating the foundational conditions that promote everyday liveability and sustainability. While we strongly advocate a holistic perspective, we will discuss each domain separately to highlight the implications of our findings as a means to inform the efforts of stakeholders interested in creating urban spaces and dwellings that are more liveable and sustainable places.

Table 1. Key aspects of individual dwelling, building complex and community that contribute to liveability

\begin{tabular}{lll}
\hline Individual Dwelling & Building Complex & Community \\
\hline - Thermal & - Shared space & $\bullet$ Accessible transport \\
comfort/ventilation & $\bullet$ Good neighbour & $\bullet$ Amenities/services \\
- Natural light and & protocols & $\bullet$ Sense of community \\
balconies & $\bullet$ Environmental & \\
N soise mitigation & sustainability & \\
\hline
\end{tabular}

\subsection{Individual Dwelling}

In considering the findings related to the individual dwelling zone, it is important to note changes that have occurred in the size of dwelling space over time within the Australian context. Until recently, the traditional Australian home was constituted by a freestanding house of around 250sqm on a 400sqm parcel of land spread out in the dormitory suburbs that sprawl around Australian cities. Thus, many Australians over the age of 30 years old grew up in homes and properties of this size. In 2008, the average floor space of new free-standing houses was 245sqm, somewhat larger than the 201sqm average size of new houses built in the United States (Australian Bureau of Statistics, 2010). While floor space in freestanding homes has tended to increase in Australia over time, the development of high-density living and migration into these areas represents a marked change for residents who grew up in 250sqm homes, since the average floor space of high-density homes is 100sqm. Participants in this study living in high density homes that are 100sqm on average, identified, thermal comfort and ventilation, natural light and noise mitigation as contributing significantly to making the home a liveable place. These findings are in keeping with research undertaken by Howley and colleagues (2009) who found that it was the related issues (e.g. noise, environmental quality, lack of community life, traffic and lack of services) with high density that lead to dissatisfaction rather than high density per se. The seeking of 
particular design features in their high-density accommodation in the present study may well reflect a desire for replicating dwelling attributes that they enjoyed in their earlier lives.

\subsubsection{Thermal Comfort and Ventilation}

Design features that enhanced thermal comfort, which include indoor air quality, temperature and humidity, emerged as being very important to study participants. Features found to contribute to thermal comfort included: natural air-flow and control over exposure to the sun's heat and light; dwellings with balconies and other outdoor living areas; internal and external modifications (e.g. shades and blinds); and orientation of the dwelling to maximise breezes during summer months and to maximise access to the sun's warmth in winter months. The nature of climate considerations will differ depending on local characteristics. Heating over ventilation may be the key factor in cooler climates, however in this subtropical climate the emphasis was on keeping cool in the humid summer months. Interestingly, participants indicated a preference for natural air flow rather than air-conditioning.

We try and use the air conditioner as little as possible... if you open the windows you get a good breeze, it's generally fine. (HD2, male aged 60-64 years)

Participants valued natural climate-efficient ways to address the heat, describing how, for sustainability reasons, they rarely used their air conditioner and relied instead on fans, windows, and cross-ventilation.

[I] open the back door and let the breeze go through. That's just the simplest form of conserving energy. Most people would go and turn the air conditioner on. Well, yeah, there are times in the year where I have to do that but, you do simple things with what you've got to reduce the amount of energy you take to live there and you find that you can live more cheaply and very, very comfortably. (HD1, male aged 45-49 years)

This is in keeping with Australian research in Sydney on thermal comfort which has shown high occupant comfort satisfaction scores in naturally ventilated mixed-mode buildings with sustainability dividends of reduced energy use by a quarter (Rowe, 1996) and occupants being comfortable in temperatures that closely reflect the outdoor climate (Artkins, 2007). Thus, passive temperature control is an extremely desirable dwelling characteristic that should be prioritised by developers and designers.

\subsubsection{Natural Light and Balconies}

The importance of exposure to abundant natural light for its aesthetic, thermal and lighting value was emphasised by residents. Most rooms in traditional Australian homes have windows that allow for natural lighting and ventilation (Australian Government, 2010). Participants associated natural light with not only sunlight and heating, but also with a 'feeling' of more open space, therefore creating a more comfortable, liveable and aesthetically pleasing dwelling interior. Participants were generally satisfied with natural light in their dwelling.

It's excellent. Because we get mainly southern light...unfortunately we don't get direct sunlight until the afternoon, because the sun comes over this way... So it would have 
been nice to get more sun maybe in the morning, but there's not much we can do about that. (HD20, male aged 30-34 years)

Many traditional Australian homes were characterised by broad verandahs shaded by corrugated iron roofing and timber lattice which were important features for cooling the home by providing breezeways (Australian Government, 2010). Most participants indicated that balconies in high density dwellings were also important for enhancing natural air-flow and improving thermal comfort, identifying balconies as being important for improving natural light and maintaining a connection with the outdoor environment. Natural light was seen as a desirable feature, creating a more comfortable, liveable and aesthetically pleasing dwelling interior. Part of a dwelling's liveability was the connection to the outdoor environment, important for high density residents and achieved through open windows and balcony areas. Verandahs or balconies have been identified as very important space for social relations that also act as buffer zones of gentle transition between public and private space (J. Williams, 2005). A study by Mulholland Research and Consulting (2003) found that balconies were valued for relaxing outdoors especially when they had a sunny aspect. Many participants in the current study identified the balcony and associated open space and views as their favourite design feature of the dwelling.

I think [my favourite design feature of this apartment is] the balcony and the glass windows because it's private... and just the open space of it”. (HD20, male aged 30-34 years)

Previous research has shown the beneficial social and psychological effects of building designs that feature natural light and views of natural surrounds, including reduction in stress, better emotional health, improved communication and a sense of belonging to a community or place (Heerwagen \& Zagreus, 2005; Vallance, Perkins, \& Moore, 2005). The challenge for designers and developers in a subtropical climate is to balance daylight penetration and maximise the positive outcomes of daylight while minimising the negative impacts of solar heat gain or noise or fumes from traffic in the public realm.

\subsubsection{Noise Mitigation}

Levels of annoyance are associated with various sources of noise in high density urban areas and managing noise is crucial for enhancing satisfaction with high density living (Bramley \& Power, 2009; Saville Smith, 2010). Noise is generated internally within a building (e.g. noise from surrounding neighbours' voices, music or appliances) or externally (e.g. traffic noise industrial activities or surrounding neighbours). Noise can also be classified as either air-borne (through openings, closed windows, doors, walls and floors) or structure-borne (through building materials from sound sources such as vehicular or foot traffic, banging, or objects dropped), with design solutions not always being the same (Australian Government, 2002). For these participants, although motor vehicle noise was the most commonly heard noise, it was voices, music or sounds from animals that were identified as the most annoying noises. This is in keeping with research undertaken by Williams (2000). Williams (2000) found some evidence of increases in "bad neighbour" effects of noise complaints although causal attribution was difficult to substantiate. Varying tolerance to these different types of 
noise may result from the nature of the noise, be it constant, intermittent, anonymous or identifiable, as well as the time of day in which it occurs.

There has been a move in recent years for unit owners to change their floors to timber. The buildings were built with carpet flooring and owners have been changing them to timber and it's caused a lot of disputes in a lot of buildings, you may have heard of other cases, and that is causing problems. Units on both sides of us have converted their floors to timber and as a result we're getting noise transference through which we used not to get. (HD16, male aged 70-74 years)

Being aware of how noise travels within a building is important for noise management, both from a building design point of view and the residents' perspective of wishing to minimise noise, thereby contributing to greater satisfaction with high density living (Saville Smith, 2010; Vallance, et al., 2005). While it is important to insulate and provide barriers against noise, it is also important to look at measures to control noise at the source.

\subsection{Building Complex}

The building in which dwellings are located was discussed in relation to liveability within high density urban areas, with shared space, good neighbour protocols and environmental sustainability identified as key aspects of building design.

\subsubsection{Limited Use of Shared Space}

The social impacts of high density include the necessity to use shared space for everyday activity due to reduced private space (Ancell \& Thompson-Fawcett, 2008). Shared space includes areas in multi-unit dwellings and apartments that can be accessed by all residents. This includes outdoor amenity areas such as swimming pools, gyms and children's play areas as well as indoor shared access areas such as corridors, lifts and stairwells. Mulholland Research and Consulting (2003) identified outdoor space as vital to making high density liveable for a wide cross-section of people. Access to communal facilities was considered useful to those interviewed in the current study, with over half indicating they were satisfied with the communal facilities (pool, barbeques, decks, clotheslines, etc) within their building complex. However, communal facilities within the building were used infrequently. For example, most have a swimming pool in their building and yet indicated that they never or infrequently used it or other shared facilities, such as barbeques and deck areas.

I'm ashamed to say I've never used the pool, but I'm not really one to use the pool. Except when I've stood around it for drinks and common social gatherings (HD11, male aged 70-74 years)

The social interaction of those interviewed in the current study included brief, trivial and small exchanges. Many of the participants said they liked to keep to themselves and valued privacy in shared areas, indicating that they were happy to maintain a simple 'hello' relationship with their neighbours but did not want to feel pressure or any obligation to talk to neighbours. 
I like that when we go out, we don't have to stand and have a little chat every five minutes. You can just come and do your own thing (HD6, female aged 25-29 years)

Such findings are consistent with an emerging body of research, which suggests there is little social contact within high density residential communities (J. Williams, 2005; Zhang \& Lawson, 2009). How high rise developments are designed can influence the sense of social connectedness between residents. There can be restricted opportunity for residents to spontaneously participate in short term and spur-of-the-moment activities because of limited space for eating or playing games or sport outside of the apartment but within the building complex (Henderson-Wilson, 2008). Previous research has found that large numbers of other occupants can cause residents to withdraw and refuse to participate in community activities (Adams, 1992; J. Williams, 2005) . Critically, however, this research suggests that it is residents themselves who choose to maintain distance between themselves and others in order to maintain their privacy. While further research would be needed to more fully explore their motivations in this regard, these findings suggest that residents choose to remain 'friendly strangers' because of their strong desire for privacy within their home.

\subsubsection{Good Neighbour Protocols}

Many Australians accustomed to living in detached houses on larger blocks of land may find it confronting or difficult to live in shared proximity with others. High density buildings and facilities are covered by community title laws that allow Body Corporates and other management structures to develop guidelines for shared facilities, which include management of noise, behaviour around common areas such as pools and use of shared parking areas (Queensland Government, 2010). Some participants indicated a level of voluntary behaviour towards neighbours, explaining that they engaged in social adaptation and reciprocity in high density dwellings, by monitoring their own behaviour (e.g. noise generated) and being tolerant of particular neighbour behaviour such as routine and expected noises. A study undertaken by Mulholland Research and Consulting (2003) found that residents were very aware of the needs of their neighbours and adjusted their own behaviour accordingly. They identified a strong spirit of community organisation and agreement on core shared values aimed at protecting privacy (Mulholland Research and Consulting, 2003). In the present study, limited tolerance was displayed for particular neighbour behaviours that were not deemed as 'acceptable' however, which were described as generating noise early in the morning or late at night, loudly exiting and entering the building, pet noise and disregard for allotted car-parking spaces.

I think each of us have just realised this is the way that it is and we just have to be a bit considerate. I mean, I have been lucky...I don't have a party animal living upstairs who likes to have music blaring and his mates around every Saturday night to watch the footy. So the people that have been upstairs, previously there was an older person and then more recently a younger couple. I actually said to them can you hear my TV and they said yeah, can you hear us talking? And I said, I think that's just the way it is and we just have to live with it. And they said 'yeah'. (HD1, male aged 45-49 years) 
Residents placed value on 'good neighbour protocols' and most were aware of how their behaviour impacted on others and engaged in voluntary mitigation activities. These findings align with those of Williams (2000) and her description of the "bad neighbour" and Saville-Smith (2010) who identified the built environment key determinants of neighbourhood satisfaction. The elements identified by Saville-Smith (2010) and Williams (2000) were the same as those identified by the current study's participants including low noise and other disturbance when living in close physical proximity with other residents. These findings highlight the value of developing and disseminating a 'code of behaviour' for building residents that explains, especially for new high density residents, how seemingly innocuous behaviours may negatively impact upon their neighbours' quality of life.

\subsubsection{Environmental Sustainability}

Environmental sustainability for high density buildings and complexes may involve a range of initiatives such as recycling bins, installing water efficient fixtures in dwellings and common areas, planning garden spaces with limited need for watering, and designing dwellings and common areas that utilise daylight, natural air-flow and passive heating and cooling (Queensland Government, 2009). Participants were aware of environmental sustainability and some believed utilising less space by living in higher density dwellings led to more sustainable use of resources. However, many voiced concerns over the lack of sustainability initiatives within their building and indicated that there was significant room for improvement in the provision of recycling facilities.

I've got 2 wine bottles by my door for me to take them down and throw in the... garbage. I feel guilty throwing glass in the garbage because I've been so used to [recycling], you just don't do it here. There's no facility to do it (HD15, female 30-34 years)

Providing opportunities for efficient waste, water and energy management through environmental sustainability initiatives is important to residents. Many of these building initiatives have been identified earlier as contributing to the liveability of the dwelling (e.g. building design capturing daylight and providing cross ventilation to reduce reliance on artificial lighting, heating and cooling), with past research also finding that sustainable cities are considered to be high quality liveable places where people want to live (Bishop \& Syme, 1995).

\subsection{Community}

Community is the third major domain that is integral to liveable or sustainable places. Communal outdoor space in high density is important compensation for the necessary restriction on private outdoor space (Mulholland Research and Consulting, 2003; J. Williams, 2005). Good management and skilful design are required to ensure that community space meets the needs of different residents (McCrea \& Walters, 2012; Mulholland Research and Consulting, 2003). Participants in the current study described the community aspect of liveability as including accessible and sustainable transport, amenities and services, and a sense of neighbourhood community. Many said they decided to live in the area because of the 
availability of public transport and accessibility to the neighbourhood community amenity (including foot and bike paths), explaining that residential complex selection was based on its location with respect to the city centre, facilities in the neighbourhood and facilities within the design of the residential complex.

\subsubsection{Accessible and sustainable transport}

The majority of participants agreed that it was easy to walk to a public transport stop from their home and felt safe walking or bicycling in their neighbourhood during the day; only half felt safe walking or bicycling at night. Walking was a common mode choice for various types of journeys, with participants reporting that they walked daily or weekly, commonly for the purpose of travelling to restaurants, recreational facilities and the newsagent. In terms of community socio-spatial issues, the walkable neighbourhood ideally performs two basic functions: a movement corridor to take people to destinations where planned exchanges will take place and a 'stage' or 'outdoor living room' to facilitate exchanges both planned and spontaneous (Engwicht, 1999). In the current study, walking was preferred for reaching certain destinations, providing ease of access to local services, a sense of the surrounding community and, for some, a reduced environmental impact.

Walking around the streets at night I do, coming back from the cinema, it's just dead quiet. After ten o'clock at night, the amount of traffic on the road is significantly less, so there's hardly any traffic noise, surprisingly. So yeah, there's just this feeling of peace and quiet and safety. (HD1, male aged 45-49 years)

Yet, while most thought public transport was available and convenient, cars emerged as the preferred travel mode for many journeys - most participants reported travelling by car regularly (daily or several times weekly).

I suppose what's not great is there's not that many local shops, so if you do have to go and do grocery shopping, you've got to get in the car and get somewhere. Public transport is not that crash hot, if you don't want to go to the city. (HD14, male 45-49 years)

The availability of everyday amenities is necessary to encourage residents to walk in their neighbourhood (de Certeau, Giard, \& Mayol, 1998). Access to amenities that facilitate participation in everyday type activities (e.g. retail shopping) appears for these participants to be principally undertaken with the use of a private motor vehicle.

\subsubsection{Amenities and Services}

Providing services within the community has been linked to residential satisfaction and quality of life (Lloyd \& Auld, 2003). Participants in this study explained that having access to amenities (local services and recreational facilities) in their local area was considered very important in high density neighbourhoods.

It's the area. It's the fact that, two minutes and I've got twenty odd restaurants to go to. I can see work from here. I get the bus to work. I can walk to get my haircut, see my doctor, walk, walk, walk. (HD3, male aged 50-54 years) 
While these findings suggest that access to amenities is a key driver of satisfaction with locality, the findings also suggest that not all areas of ICHD Brisbane are well served with a rich supply of amenities. Many areas of inner-city Brisbane have evolved from semi-industrial, brownfield sites of typically contaminated areas with minimal amenity to high density residential neighbourhoods. While brownfield projects are key strategies for compacting cities they are time-consuming to develop (Crewe \& Forsyth, 2011). Development of necessary infrastructure (such as amenities and public transport) that keeps pace with the needs of residents in high growth areas represents a major challenge, given that neighbourhoods usually develop incrementally as social, physical and economic structures (Banks \& Shenton, 2001). Residents of neighbourhoods with little or no available amenities are required to drive to other neighbourhoods for their everyday needs. Williams (2005) found that her study participants spent on average 38 per cent of their time per month outside their neighbourhood community. Such behaviour is not in keeping with the liveability and sustainability goals of a compact city of short walkable distances.

\subsubsection{Sense of Community}

Although participants describe liveable and sustainable aspects of their inner urban community, they were not likely to have strong connections with their neighbours. As mentioned above, these findings are consistent with previous studies (J. Williams, 2005; Zhang \& Lawson, 2009) where very few of those interviewed were well acquainted with other neighbours and their interaction was mostly brief, trivial and regularly involved practical, small exchanges. Williams (2005) found in her study that participants spent 6 per cent of their time in communal, semi-private space and 4.45 per cent of their time per month in social interaction with others in their community. In the present study, most participants had not visited a neighbour in the past week, had not attended a local community event in the past six months and did not think they would run into friends and acquaintances when they went shopping in their local area. While residents may not form strong relationships with their immediate neighbours, they do seem to enjoy the sense of community derived from their broader neighbourhood through easy access to local goods and services (where they are available) and a sense of familiarity with the area, as well as people working or living in the area.

I think [high-density living] is good, because it just ... brings people together, and I think it makes communities ... Because I think it's a myth, this whole thing about, being out and having a house, and getting to know the neighbours, and... I think it's more social living here, [with] shared services, like there's one pool for everyone, instead of everyone having to have their own pool, everyone having to have their own lawn mower... I think it makes more sense to live in a... high-density apartment like that. And then, basically have parks around which everyone can use. (HD20, male 30-34 years)

For urban planners, these findings suggest that access to amenities is a key driver of satisfaction with locality and are consistent with the concept of 'complete communities'. 'Complete communities' refers to liveable places characterised by mixed land uses, as well as 
walkable and pedestrian friendly environments equipped with amenities and services that foster local self-sufficiency, meaningful place-based identity, attachment and ownership (Perkins, 1995). This research suggests that ICHD Brisbane residents strongly value many of the characteristics of 'complete communities', particularly easy, accessible connections between their homes, shopping, walkways, cycle paths and public transport. These characteristics, however, are not equally shared across this study's ICHD neighbourhoods causing residents in neighbourhoods with few or no amenities to drive to other neighbourhoods for their everyday needs.

\section{Conclusion}

Howley et al. (2009) suggest that a city can be both high density and offer high quality living space but to achieve this, compact city policy makers must deal specifically with the critical link between design and density with greater emphasis on liveability. For the compact city to be a desirable planning goal, the individual dwelling, building complex and community must be carefully designed and built in such a way as to accommodate residents' social, environmental and economic needs that are integral to a liveable and sustainable ICHD environment. This suggests a significant role for designers and urban planners because neighbourhood design and good quality delivery of services and amenities can ease many of the problems related to high density (Howley, et al., 2009).

The interplay of the relationships between policy, place and daily life must be better understood to facilitate the successful introduction of liveability and sustainability policy (Vallance, et al., 2005). This paper presupposes that the physical form of ICHD as space should address all aspects of residents' liveability and sustainability needs including social needs. While there is much debate regarding the extent to which development of the built elements are able to fulfill social needs there is also the recognition that physical and social aspects of the city are undeniably interlinked (Ancell \& Thompson-Fawcett, 2008).

This study identifies significant synergy between the aspirations of customers' and those of society. The results show that urban features that reflect current societal pressure for greater sustainability such as lower energy use and more use of public transport are the exact same features sought by residents in determining the liveability of a particular community. From the dwelling perspective, enhanced thermal comfort and improved air-flow and natural lighting would significantly reduce the need to artificially heat, cool and light these homes. Within the building complex, shared space, good neighbour protocols and environmental sustainability were the key issues that affect ICHD liveability for residents. In the community realm, improved public transport and walkability infrastructure in inner urban areas would provide community dividends of increased sustainability from making public transport and walkability more appealing. These findings highlight a number of opportunities for regulators, developers and designers to incorporate design features that not only enhance the liveability of high density residences, but also their long term sustainability.

Sustainability and community dividends arising from better design of high density dwellings, buildings and urban areas identified by this study suggest the need for regulators to re-examine building codes and guidelines. Future building codes or guidelines that address 
issues raised by this study's ICHD residents could make dwellings, buildings and urban areas more liveable and sustainable from a user and community perspective. Implementation of many of the findings of this study could assist in reducing energy use and $\mathrm{CO}^{2}$ emissions, while at the same time enhancing the liveability of inner urban high density dwellings. The relevance of these findings are not restricted to the study site since they are likely to extend to other major subtropical cities throughout the world.

Attributes and qualities that contribute to the liveability and sustainability of high density environments have been explored in this paper. While it is intrinsically tempting to focus on the immediacy of the present day liveability rather than the sustainability of some distant future, we argue that efforts to attain liveability and sustainability need not be at cross-purposes with one another. Rather, they can work in tandem to ensure the needs of the present are viewed more expansively and proactively in effecting preferred future outcomes. Considerable synergy between the aspirations of residents and those of society were identified. The data showed that urban features that reflect current societal pressure for greater sustainability such as lower energy use and more use of public transport are the same features sought by residents in describing the liveability of a particular community.

This research is both pertinent and timely. The study is grounded in local reality and highlights pertinent built environment challenges for potential policy and planning action. While the study reports on the experiences of a small number of high density residents living in one city in Australia thereby precluding generalisability of its findings, it captures the local knowledge and place-based cultures of everyday use for this group of ICHD residents providing insight into their lived experience. Such results tend to be more relevant and are more likely to be actioned than abstract generalities about liveability requirements (Myers, 1987; National Research Council, 2002; Stevens, 2006). Their experiences are also likely to have relevance to other high density contexts elsewhere without having to discount for local differences. However, further research is needed that explores, in more depth, how people, both residents and non-residents, view, experience and judge ICHD areas. In particular, future research should explicitly explore the extent to which characteristics of the dwelling (small size) and/or the amenities, services and recreational facilities within the neighbourhood either facilitate or hinder ICHD localities being accessible and socially inclusive places for all members of the community. Our results suggest that encouraging more inner-city retail, particularly services which are utilised frequently in people's daily lives such as grocers and pharmacies, would potentially help ensure residents fully engage in their local community and also attract a more diverse local population.

As stated above, a liveable place is a complex concept, very personal and often therefore difficult to articulate. It is a multi-faceted concept capturing many attributes which interplay and operate dynamically within and between the immediate living environment, the building and the community. These attributes provide the essential services and life enriching amenities and experiences within close proximity for its residents and visitors. Understanding the factors that influence residents' perceptions of liveability of ICHD locations can assist with the planning, management and design of high density residential complexes and locations to create liveable, supportive and sustainable cities. 


\section{Acknowledgments}

This research was funded by an Australian Research Council (ARC) Linkage Project, "Managing the social, environmental and economic impacts of high density-living within inner-urban sub-tropical environments”.

\section{References}

Adams, R. E. (1992). Is happiness a home in the suburbs?: The influence of urban versus suburban neighborhoods on psychological health. Journal of Community Psychology, 20(4), 353-372.

http://dx.doi.org/10.1002/1520-6629(199210)20:4<353::AID-JCOP2290200409>3.0.CO ;2-Z

Ancell, S., \& Thompson-Fawcett, M. (2008). The Social Sustainability of Medium Density Housing: A Conceptual Model and Christchurch Case Study. Housing Studies, 23(3), 423-442. http://dx.doi.org/10.1080/02673030802029990

Andrews, C. J. (2001). Analyzing Quality of Place. Environment \& Planning B: Planning \& Design, 28, 201-217. http://dx.doi.org/10.1068/b2714

Artkins, C. (2007). All in the Mind. Essential Matters Retrieved 3 March 2010, from http://www.essentialmatters.com.au/resources/PropAust_Issue10_p68_69.pdf

Australian Bureau of Statistics. (2010). Year Book Australia, 2009-10, Electronic Resource, Catalogue Number: 1301.0, Retrieved from http://www.abs.gov.au/ausstats/abs@.nsf/cat/1301.0

Australian Government. (2002). State of the Environment Report 2001 Retrieved 16 October 2009, from

http://www.environment.gov.au/soe/2001/publications/themereports/settlements/settlem ents04-2.html

Australian Government. (2010). Australian Architecture - Australian Government Cultural Portal Retrieved 10 May 2010, from http://www.cultureandrecreation.gov.au/articles/architecture/,

Bakardjieva, M. (2003). Virtual Togetherness: an Everyday-life Perspective. Media Culture Society, 25(3), 291-313. http://dx.doi.org/10.1177/0163443703025003001

Banks, S., \& Shenton, F. (2001). Regenerating Neighbourhoods: A Critical Look at the Role of Community Capacity Building. Local Economy: The Journal of the Local Economy Policy Unit, 16(4), 286-298. http://dx.doi.org/10.1080/02690940110078265

Bishop, B. J., \& Syme, G. J. (1995). The social costs and benefits of urban consolidation: A time budget/contingent valuation approach. Journal of Economic Psychology, 16(2), 223-245. http://dx.doi.org/10.1016/0167-4870(95)00006-A 
Bramley, G., \& Power, S. (2009). Urban form and social sustainability: the role of density and housing type. Environment and Planning B: Planning and Design, 36(1), 30-48. http://dx.doi.org/10.1068/b33129

Chiesura, A. (2004). The role of urban parks for the sustainable city. Landscape and Urban Planning, 68(1), 129-138. http://dx.doi.org/10.1016/j.landurbplan.2003.08.003

Crewe, K., \& Forsyth, A. (2011). Compactness and connection in environmental design: insights from ecoburbs and ecocities for design with nature. Environment and Planning B: Planning and Design, 38(2), 267-288. http://dx.doi.org/10.1068/b35131

de Certeau, M., Giard, L., \& Mayol, P. (1998). The Practice of Everyday Life, Volume 2: Living and Cooking. Minneapolis MN: University of Minnesota Press.

Diener, E., Oishi, S., \& Lucas, R. E. (2003). Personality, Culture, and Subjective Well-Being: Emotional and Cognitive Evaluations of Life. Annual Review of Psychology, 54(1), 403-425. http://dx.doi.org/10.1146/annurev.psych.54.101601.145056

Engwicht, D. (1999). Street reclaiming : creating livable streets and vibrant communities. Annandale, NSW: Pluto Press.

Evans, P. (2002). Livable Cities? Urban Struggles for Livelihood and Sustainability. Berkeley: University of California Press.

Gleeson, B., \& Steele, W. (2010). A climate for growth: Planning South-East Queensland. Brisbane: UQ Press.

Grant, J. (2006). Planning the good community : new urbanism in theory and practice. London; New York: Routledge.

Grant, J. (2006a). The Ironies of New Urbanism. Canadian Journal of Urban Research, 15(2), 158-174.

Hampshire, A. (2000). Stronger communities and social connectedness - social capital in practice. Paper presented at the The Council on the Ageing National Congress.

Heerwagen, J., \& Zagreus, L. (2005). The Human Factors of Sustainable Building Design: Post Occupancy Evaluation of the Philip Merrill Environmental Center: US Department of Energy Building Technology Program.

Henderson-Wilson, C. (2008, 18-20 June 2008). Inner city high-rise living: a catalyst for social exclusion and social connectedness? Paper presented at the 3rd Australasian Housing Researchers' Conference 2008, Melbourne.

Howley, P., Scott, M., \& Redmond, D. (2009). Sustainability versus liveability: an investigation of neighbourhood satisfaction. Journal of Environmental Planning and Management, 52(6), 847-864. http://dx.doi.org/10.1080/09640560903083798

Jacobs, J. (1961). The Death and Life of Great American Cities. London: Jonathan Cape. 
Lefebvre, H. (1991). Everyday Life in the Modern World. New Brunswick NJ: Transaction Publishers.

Liamputtong, P., \& Ezzy, D. (2005). Qualitative research methods. . South Melbourne: Oxford University Press.

Lloyd, K., \& Auld, C. (2003). Leisure, public space and quality of life in the urban environment. Urban Policy and Research, 21(4), 339-356. http://dx.doi.org/10.1080/0811114032000147395

Lovejoy, K., Handy, S., \& Mokhtarian, P. (2010). Neighborhood satisfaction in suburban versus traditional environments: An evaluation of contributing characteristics in eight California neighborhoods. Landscape and Urban Planning, 97(1), 37-48. http://dx.doi.org/10.1016/j.landurbplan.2010.04.010

Lu, M. (1999). Determinants of Residential Satisfaction: Ordered Logit vs. Regression Models. Growth \& Change, 30(2), 264. http://dx.doi.org/10.1111/0017-4815.00113

Lynch, K. (1981). Good City Form Cambridge, MA: MIT Press.

McCrea, R., \& Walters, P. (2012). Impacts of Urban Consolidation on Urban Liveability: Comparing an Inner and Outer Suburb in Brisbane, Australia. Housing, Theory and Society, 29(2), 190-206. http://dx.doi.org/10.1080/14036096.2011.641261

Mulholland Research and Consulting. (2003). Perceptions of Privacy and Density in Housing. London: Design for Homes Popular Housing Research.

Myers, D. (1987). Community-Relevant Measurement of Quality of Life: A Focus on Local Trends. Urban Affairs Quarterly, 23(1), 108-125. http://dx.doi.org/10.1177/004208168702300107

Myers, D. (1988). Building Knowledge about Quality of Life for Urban Planning. Journal of American Planning Association, 54(3), 347-358. http://dx.doi.org/10.1080/01944368808976495

Myers, D. (1989). The Ecology of 'Quality of Life' and Urban Growth. In D. J. Brower \& D. R. Godschalk (Eds.), Understanding Growth Management: Critical Issues and Research Agenda. Washington, DC: Urban Land Institute.

National Research Council. (2002). Community and Quality of Life: Data Needs for Informed Decision-Making. Washington, DC: Board on Earth Sciences and Resources, Division on Earth and Life Studies, National Research Council, National Academy Press.

Neilson, L. (2008). The 'Building Better Cities' Program 1991-1996: a nation-building initiative of the Commonwealth Government. In J. Butcher (Ed.), Australia under construction nation-building - past, present and future (pp. 83-118). Canberra: ANU E Press.

Newman, D. M. (2008). Sociology : exploring the architecture of everyday life Thousand Oaks, Calif: Pine Forge Press 
Pacione, M. (1990). Urban liveability: A review. Urban Geography, 11(1), 1-30. http://dx.doi.org/10.2747/0272-3638.11.1.1

Pacione, M. (2003). Urban environmental quality and human wellbeing-a social geographical perspective. Landscape and Urban Planning, 65(1-2), 19-30. http://dx.doi.org/10.1016/S0169-2046(02)00234-7

Perkins, R. (1995). Vancouver: Complete Communities for the Liveable Region Intensification Report: Canadian Urban Institute.

Queensland Government. (2009). Climate Q: Toward a greener Queensland, 2009 Retrieved 16 September 2009, from

http://www.climatechange.qld.gov.au/pdf/climateqreport/climateqreport.pdf

Queensland Government. (2010). Body Corporate and Community Management Act 1997. Brisbane: Office of the Queensland Parliamentary Counsel,.

Rowe, D. (1996). Mixed Mode Climate Control AIRAH Journal : Australian refrigeration, air conditioning \& heating, 50(12).

Rowley, A. (1998). Private-property decision makers and the quality of urban design. Journal of Urban Design, 3(2), 151. http://dx.doi.org/10.1080/13574809808724423

Saville Smith, K. (2010, 4-7 July 2010). The Value of Neighbourhood Intensification: The Interface Between Dwelling, Neighbourhood Design and Affordability. Paper presented at the ENHR 22nd International Housing Research Conference: Urban Dynamics \& Housing Change - Crossing into the 2nd Decade of the 3rd Millennium, Istanbul.

Schmandt, H. J., \& Bloomberg, W. (1969). The quality of urban life Beverly Hills CA: Sage.

Sirgy, M. J., \& Cornwell, T. (2002). How neighborhood features affect quality of life. Social Indicators Research, 59(1), 79. http://dx.doi.org/10.1023/A:1016021108513

Smart State Council. (2007). Smart Cities: rethinking the city centre. Brisbane: Queensland Government.

Southworth, M., \& Parthasarathy, B. (1996). The suburban public realm I: Its emergence, growth and transformation in the American metropolis. Journal of Urban Design, 1(3), 245-263. http://dx.doi.org/10.1080/13574809608724385

Stevens, Q. (2006). The shape of urban experience: a reevaluation of Lynch?s five elements. Environment and Planning B: Planning and Design, 33(6), 803-823. http://dx.doi.org/10.1068/b32043

Vallance, S., Perkins, H. C., \& Moore, K. (2005). The results of making a city more compact: neighbours? interpretation of urban infill. Environment and Planning B: Planning and Design, 32(5), 715-733. http://dx.doi.org/10.1068/b31157

Van Assche, J., Block, T., \& Reynaert, H. (2010). Can Community Indicators Live Up to Their Expectations? The Case of the Flemish City Monitor for Livable and Sustainable 
Urban Development. Applied Research in Quality of Life, 5(4), 341-352. http://dx.doi.org/10.1007/s11482-010-9121-7

Wheeler, S. (1999). Planning Sustainable and Livable Cites. In R. T. LeGates \& F. Stout (Eds.), The City Reader (pp. 434-445). London Routledge.

Whyte, W. H. (1988). City: Rediscovering the Center. New York, London: Doubleday.

Whyte, W. H. (2001). The Social Life of Small Urban Spaces. New York: Project for Public Spaces.

Williams, J. (2005). Designing Neighbourhoods for Social Interaction: The Case of Cohousing. Journal of Urban Design, 10(2), 195-227. http://dx.doi.org/10.1080/13574800500086998

Williams, K. (2000). Does intensifying cities make them more sustainable. In K. Williams, L. Burton \& M. Jenks (Eds.), Achieving Sustainable Urban Forms (pp. 30-45). London: Spon.

Zhang, W., \& Lawson, G. (2009). Meeting and greeting: Activities in public outdoor spaces outside high-density urban residential communities. Urban Design International, 14(4), 207-214. http://dx.doi.org/10.1057/udi.2009.19

\section{Copyright Disclaimer}

Copyright reserved by the author(s).

This article is an open-access article distributed under the terms and conditions of the Creative Commons Attribution license (http://creativecommons.org/licenses/by/3.0/). 